\title{
STUDIES OF IODOALBUMIN METABOLISM. II. THE EFFECTS OF THYROID HORMONE*
}

\author{
By CHARLES G. LEWALLEN, $\uparrow$ JOSEPH E. RALL, $\dagger$ AND MONES BERMAN $\dagger$ \\ (From the Medical Department, Brookhaven National Laboratory, Upton, N. Y.; the National Institute of \\ Arthritis and Metabolic Diseases, National Institutes of Health, Bethesda, Md.; and the \\ Division of Biophysics, Sloan-Kettering Institute of the Memorial Center \\ for Cancer and Allied Diseases, New York, N. Y.)
}

(Submitted for publication May 21, 1958; accepted September 18, 1958)

The profound effects of thyroid hormone on a variety of metabolic systems have been well documented. In this report evidence that thyroid hormone alters the distribution kinetics and degradation of iodoalbumin in man is presented. The results of these studies have been previously presented in a preliminary report, prior to refinement of the mathematical analysis employed (1).

\section{METHODS}

General. The I ${ }^{131}$ labeled human serum albumin used in these studies was the commercial preparation of Abbott Laboratories obtained between May, 1953, and May, 1954. Prior to use, the material was suspended in redissolved lyophilized plasma and then dialyzed with a cellulose membrane to equilibrium three times against 40 times its volume of a 1:25 dilution of plasma in saline. Without added carrier protein, considerable loss of label on glassware ensued and the preparation was unstable on prolonged dialysis. Quantitation of activity in the dialysate indicated the presence in the preparation of 0.3 to 2.4 per cent dialyzable $\mathrm{I}^{131}$ prior to dialysis.

The dialyzed iodoalbumin solution was injected into the rubber tubing of a previously inserted intravenous Murphy drip of normal saline in approximately 20 seconds from a $10 \mathrm{ml}$. syringe gravimetrically calibrated to deliver with an error not exceeding 0.1 per cent. The injection was immediately followed by a 30 second rinse from the Murphy drip. The intravenous tubing was then clamped, the needle removed, and both thoroughly rinsed into a volumetric flask. Less than 0.1 per cent of the syringe dose remained in the tubing in all experiments.

Heparinized venous blood samples were taken at approximately the following times after injection: $5,10,20$ and 40 minutes; $1,2,4,6,8,12,18$ and 24 hours. In the earlier studies of Experiment I, after 24 hours, blood samples were taken every other day. In subsequent studies, samples were taken daily. In Experiment I samples were collected for 14 days; in Experiment II, for 36 days.

* This research was supported in part by the Atomic Energy Commission.

† Present address: National Institute of Arthritis and Metabolic Diseases, National Institutes of Health, Bethesda, Md.
The heparinized plasma was separated promptly by centrifugation and $1 \mathrm{ml}$. or $3 \mathrm{ml}$. samples counted in $4 \mathrm{ml}$. vials in series with a standard of the same volume consisting of a suitable dilution of the injection suspension in plasma. Volumetric glassware was of precision grade. The counter used was a thallium activated sodium iodide scintillation crystal of the well type. Appropriate corrections were made for coincidence loss. Radioactivity was expressed as fraction of the injected dose.

Total urine collections were made at 24 hour intervals throughout the studies in Experiments I and II, in glass jars containing a few pellets of sodium hydroxide, $5 \mathrm{ml}$. of toluene, and $4 \mathrm{Gm}$. of sodium iodide. Counting of aliquots and expression of radioactivity were the same as for plasma. At varying intervals, plasma samples were taken for determination of albumin by sodium sulfate fractionation (2) and gasometric determination of albumin nitrogen after Kjeldahl digestion (3).

Records were kept of the total volumes of blood withdrawn for any reason during the experiments and hematocrits were determined not less frequently than once a week. It was thus possible to compute the fraction of the injected dose removed in blood sampling. In Experiments I and II this amounted to less than 0.01 of the dose and was disregarded in subsequent calculations.

Selection of patients and description of experiments. Two experiments carried out on six patients comprise the basis of this report. Some aspects of these experiments have been discussed in another report (4).

All the patients were under observation for treatment of histologically proven thyroid carcinoma. All had previously had either surgical removal or I ${ }^{131}$ radiation-destruction of their thyroids or both as part of their therapeutic regimen. The myxedematous state was induced by prolonged deprivation of thyroid hormone with or without addition of antithyroid drugs in an attempt to induce therapeutically significant uptake of $\mathrm{I}^{131}$ in known or suspected cancerous deposits.

Experiment $I$. The pertinent clinical data on the fous patients (R. B., J. G., F. D. and O. H.) studied in this experiment, in both the euthyroid and myxedematous state, are summarized in Table I. Two patients (R. B. and J. G.) displayed no evidence of local recurrence or distant metastases. The pulmonary metastases of $F$. D. were not extensive roentgenologically and had been stationary on serial chest films for four years. O. H. had laryngoscopically demonstrable residual tumor in the larynx and subglottic area necessitating a permanent tracheostomy. 
EFFECT OF THYROID HORMONE ON IODOALBUMIN METABOLISM

TABLE I

General clinical status of patients studied in Experiments I and II

\begin{tabular}{|c|c|c|c|c|c|c|}
\hline $\begin{array}{l}\text { Patient } \ldots \ldots \ldots \ldots \ldots \\
\text { Age (years), sex. } \ldots \ldots \ldots\end{array}$ & $\begin{array}{l}\ldots \text { R. B. } \\
\ldots \text { 19, F }\end{array}$ & $\begin{array}{l}\text { J. G. } \\
22, \text { F }\end{array}$ & $\begin{array}{l}\text { F. D. } \\
18, F\end{array}$ & $\begin{array}{l}\text { O. H. } \\
74, \mathrm{M}\end{array}$ & $\begin{array}{l}\text { C. C. } \\
59, \mathrm{M}\end{array}$ & $\begin{array}{l}\text { E. L. } \\
60, F\end{array}$ \\
\hline $\begin{array}{l}\text { Thyroid carcinoma } \\
\text { type }\end{array}$ & $\begin{array}{l}\text { Mixed-follicular, } \\
\text { alveolar and } \\
\text { papillary }\end{array}$ & $\begin{array}{l}\text { Mixed-papillary, } \\
\text { follicular, } \\
\text { alveolar and } \\
\text { solid }\end{array}$ & $\begin{array}{l}\text { Mixed-papillary } \\
\text { and alveolar }\end{array}$ & Solid & Follicular & $\begin{array}{l}\text { Alveolar and } \\
\text { follicular }\end{array}$ \\
\hline $\begin{array}{l}\text { Apparent clinical } \\
\text { extent of carcinoma: } \\
\text { Local recurrence } \\
\text { or metastases }\end{array}$ & None & None & None & $\begin{array}{l}\text { Invasion of } \\
\text { trachea and } \\
\text { larynx }\end{array}$ & None & $\begin{array}{l}\text { Extensive } \\
\text { cervical lymph } \\
\text { node involve- } \\
\text { ment }\end{array}$ \\
\hline $\begin{array}{l}\text { Distant } \\
\text { metastases }\end{array}$ & None & None & $\begin{array}{l}\text { Bilateral, } \\
\text { basilar pul- } \\
\text { monary lesions }\end{array}$ & None & $\begin{array}{l}\text { Small osteo- } \\
\text { lytic metastasis, } \\
\text { right clavicle }\end{array}$ & $\begin{array}{l}\text { Extensive } \\
\text { sternal and } \\
\text { pulmonary } \\
\text { lesions }\end{array}$ \\
\hline $\begin{array}{l}\text { Method of } \\
\text { thyroid ablation }\end{array}$ & $\begin{array}{l}\text { Surgical total } \\
\text { thyroidectomy } \\
\text { followed by } \\
100 \text { mc. I }{ }^{131}\end{array}$ & $\begin{array}{l}\text { Surgical left } \\
\text { thyroid lobec- } \\
\text { tomy and } \\
\text { partial right } \\
\text { lobectomy } \\
\text { followed by } \\
78 \text { mc. I'131 }\end{array}$ & $\begin{array}{l}\text { Surgical right } \\
\text { thyroid lobec- } \\
\text { tomy followed } \\
\text { by } 75 \mathrm{mc} . \text { I }^{131}\end{array}$ & $\begin{array}{l}\text { Surgical right } \\
\text { thyroid lobec- } \\
\text { tomy followed } \\
\text { by } 67 \mathrm{mc} \text { I }^{131}\end{array}$ & $78 \mathrm{mc} . \mathrm{I}^{131}$ & 75 mc. I $I^{131}$ \\
\hline $\begin{array}{l}\text { Additional } \\
\text { disease }\end{array}$ & $\begin{array}{l}\text { Hypopara- } \\
\text { thyroidism. } \\
\text { Mental } \\
\text { retardation }\end{array}$ & None & None & $\begin{array}{l}\text { Generalized } \\
\text { arterio- } \\
\text { sclerosis. } \\
\text { Prostatic } \\
\text { hypertrophy }\end{array}$ & $\begin{array}{l}\text { Quiescent duo- } \\
\text { denal ulcer. } \\
\text { Arterio- } \\
\text { sclerotic } \\
\text { heart disease, } \\
\text { functional } \\
\text { capacity } \\
\text { Class I }\end{array}$ & $\begin{array}{l}\text { Arteriosclerotic } \\
\text { heart disease, } \\
\text { functional } \\
\text { capacity } \\
\text { Class II }\end{array}$ \\
\hline
\end{tabular}

At the time of the first iodoalbumin study, all four patients had gross clinical evidences of myxedema. Throughout the study all were fully ambulatory and in good general physical condition, except for the manifestations of myxedema.

In three of the patients (R. B., J. G. and F. D.), addition of antithyroid drugs was not necessary for the induction of myxedema. This alone is fairly good presumptive evidence of the virtual absence of functioning thyroidal tissue. In Patient O. H. it was necessary to add an antithyroid drug (thiouracil) to induce myxedema. This patient, the only one of the four, received therapeutic ${ }^{13 t}$ between the first and second iodoalbumin tracer studies.

When the presence of myxedema had been established on clinical and laboratory grounds, the first iodoalbumin study was carried out. Later, following return to an apparently euthyroid state and at a time when the body weight was steady, the second tracer study was performed. Data relevant to the metabolic status of the four patients at the time of the studies is given in Table II.

The rate of urinary excretion of ${ }^{131}$ reflects the rate of degradation of iodoalbumin only in the absence of signifcant nonrenal loss of $\mathrm{I}^{131}$, and in the absence of entry of the liberated $\mathrm{I}^{131}$ into thyroidal iodine metabolism with consequent delay in excretion. For this reason it is desirable to block the uptake of iodide by the thyroidal system during an iodoprotein tracer study. Patients R. B. and O. H. received Tapazole ${ }^{\circledR}$ and thiouracil, respectively, during both studies. J. G. received Tapazole ${ }^{\circledR}$ during the first study. A NaI ${ }^{131}$ tracer performed shortly after the first albumin study and after withdrawal of Tapazole ${ }^{\circledR}$ showed excretion in the urine of 100 per cent of the label in four days. Accordingly no blocking agent was consid- ered necessary during the second study and none was given. Patient F. D., by oversight, received no blocking agent during the first study. However, a $\mathrm{NaI}^{131}$ tracer performed six weeks after the first study showed a urinary excretion of label of 0.96 per cent of the dose in four days. Two weeks prior to the second albumin study, this patient underwent cholecystography, a procedure known to inhibit thyroidal iodide uptake for several months. Hence, during both studies, all four patients were either receiving thyroid blocking agents or demonstrated their inability to retain $I^{131}$ presented as iodide ion in amounts exceeding 0.04 of the dose.

In Experiment I the probable error of counting of the least active plasma or urine samples was less than 1.1 per cent. The amount of tracer employed ranged from 80 to $125 \mu \mathrm{c}$.

Experiment II. This experiment was performed to study the effects of thyroid hormone on the behavior of the same batch of iodoalbumin in the same patient under different metabolic conditions. Three patients (R. B., C. C. and E. L.) were studied for a period of 36 days. The pertinent clinical background data are given in Table I. All three patients received the same preparation of iodoalbumin in a dosage of $660 \mu \mathrm{c}$. In the cases of R. B. and C. C., the metabolic status was changed on the fifteenth day by withdrawal and addition, respectively, of thyroid hormone, dividing the study into Part 1 (Days 0 to 15) and Part 2 (Days 16 to 36). Urine and plasma samples were collected and assayed as described above.

R. B. had been deprived of thyroid hormone for one month prior to the experiment and was showing distinct clinical evidence of hypothyroidism. For a four day period beginning three days prior to injection of labeled albumin, 
she was rapidly converted to a slightly hyperthyroid state by administration of $\mathrm{L}$-triiodothyronine in a daily dose of $525 \mu \mathrm{g}$. For the remainder of Part 1 of the experiment, the mean daily dose was $348 \mu \mathrm{g}$. On Day 15 the hormone was withdrawn. Within a week after its withdrawal, rather definite clinical evidence of hypothyroidism appeared. Data relevant to her changing metabolic status are shown in the lower part of Figure 4. An electrocardiogram four days prior to injection of labeled albumin showed low voltage $Q R S$ complexes and low to flat $T$ waves, characteristic of hypothyroidism. By Day 2, the tracing was normal except for sinus tachycardia. On Day 28 low voltage $Q R S$ complexes and flat $T$ waves had reappeared. In summary, the clinical picture and laboratory findings were all consistent with mild hyperthyroidism in Part 1, and rapid development of hypothyroidism in Part 2.

Throughout the experiment R. B. received Tapazole (8), $40 \mathrm{mg}$. daily, and saturated solution of potassium iodide, 15 minims daily. After completion of the iodoalbumin study, a NaI ${ }^{131}$ tracer with the patient on the same medication showed a urinary excretion of 0.955 of the label in six days.
Patient C. C. had received no thyroid medication for eight months and had been myxedematous for several months before the experiment. Part 1 of the study was carried out in the myxedematous state. On Day 15, he was started on L-triiodothyronine, $210 \mu \mathrm{g}$. daily. After five days the dosage was reduced so that the mean daily dose for Part 2 was $111 \mu \mathrm{g}$. daily. During the last eight days of the experiment desiccated thyroid, $90 \mathrm{mg}$. daily, was also given along with appropriate reduction of triiodothyronine so as to maintain a clinically euthyroid state. Data relative to the patient's changing metabolic status are shown in Figure 5. In addition, the average of 10 determinations of the basal metabolic rate (BMR) in Part 1 was -36 per cent; in Part 2, -9 per cent.

Thiouracil, started on Day 1 of the experiment, was discontinued on Day 3 because of drug rash. However, a $\mathrm{NaI}^{131}$ tracer given just prior to the albumin study showed a urinary excretion of label of 0.945 in three days.

Patient E. L. served as a control and apparently remained in a steady metabolic state throughout the 36 days of the study. Though having received several large therapeutic doses of $\mathrm{I}^{131}$ in the previous few years, she was

TABLE II

Data relevant to metabolic status of patients studied in Experiment I

\begin{tabular}{|c|c|c|c|c|c|}
\hline \multicolumn{3}{|c|}{ Patient $\ldots \ldots \ldots \ldots \ldots \ldots \ldots \ldots \ldots$ R. B. } & J. G. & F. D. & O. H. \\
\hline \multicolumn{2}{|c|}{$\begin{array}{l}\text { Period of thyroid } \\
\text { hormone deficiency } \\
\text { prior to first study } \\
\text { (months) }\end{array}$} & 5 & 5 & 5 & $\cdot$ \\
\hline $\begin{array}{l}\text { Body weight } \\
(K g .)\end{array}$ & $\begin{array}{l}(1)^{*} \\
(2)^{*}\end{array}$ & $\begin{array}{l}55.1 \\
48.5\end{array}$ & $\begin{array}{l}65.3 \\
60.8\end{array}$ & $\begin{array}{l}67.6 \\
62.0\end{array}$ & $\begin{array}{l}71.8 \\
69.6\end{array}$ \\
\hline $\begin{array}{l}\text { Serum choles- } \\
\text { terol }(m g . \%)\end{array}$ & $\begin{array}{l}(1) \\
(2)\end{array}$ & $\begin{array}{l}391 \\
148\end{array}$ & $\begin{array}{l}422 \\
254\end{array}$ & $\begin{array}{l}390 \\
140\end{array}$ & $\begin{array}{l}499 \\
313\end{array}$ \\
\hline $\begin{array}{l}\text { Protein bound } \\
\text { iodine }(\mu g . \%)\end{array}$ & $\begin{array}{l}(1) \\
(2)\end{array}$ & $\begin{array}{l}1.6 \\
8.2\end{array}$ & $\begin{array}{l}1.7 \\
5.7\end{array}$ & $\begin{array}{l}1.0 \\
4.7\end{array}$ & $\begin{array}{l}0.8 \\
7.3\end{array}$ \\
\hline $\begin{array}{l}\text { Basal metabolic } \\
\text { rate }(\%)\end{array}$ & $\begin{array}{l}(1) \\
(2)\end{array}$ & $\begin{array}{l}-45 \\
-12\end{array}$ & $\begin{array}{l}-41 \\
-20\end{array}$ & $\begin{array}{l}-44 \\
-28\end{array}$ & $\begin{array}{l}-36 \\
\text { Unsatisfactory }\end{array}$ \\
\hline \multicolumn{2}{|c|}{$\begin{array}{l}\text { Desiccated thyroid } \\
\text { dosage and duration } \\
\text { prior to second study }\end{array}$} & $\begin{array}{l}240 \text { mg. daily } \\
30 \text { days }\end{array}$ & $\begin{array}{l}120 \mathrm{mg} . \text { daily } \\
23 \text { days }\end{array}$ & $\begin{array}{l}120 \text { mg. daily } \\
30 \text { days }\end{array}$ & $\begin{array}{l}120 \mathrm{mg} . \text { daily } \\
90 \text { days }\end{array}$ \\
\hline $\begin{array}{l}\text { Thyroid block- } \\
\text { ing agent }\end{array}$ & $\begin{array}{l}(1) \\
(2)\end{array}$ & $\begin{array}{l}\text { Tapazole } \$ 40 \mathrm{mg} . \text { daily } \\
\text { Tapazole }{ }^{\circledR} 40 \mathrm{mg} \text {. daily }\end{array}$ & $\begin{array}{c}\text { Tapazole }{ }_{\text {None }} 40 \mathrm{mg} \text {. daily } \\
\text { None }\end{array}$ & $\begin{array}{c}\text { None } \\
\text { Cholecystography }\end{array}$ & $\begin{array}{l}\text { Thiouracil } 1.5 \mathrm{Gm} \text {. daily } \\
\text { Thiouracil } 1.5 \mathrm{Gm} \text {. daily }\end{array}$ \\
\hline \multicolumn{2}{|c|}{$\begin{array}{l}4 \text { day } I^{131} \text { iodide† } \\
\text { excretion (fraction } \\
\text { of dose) }\end{array}$} & & 1.00 & 0.96 & \\
\hline $\begin{array}{l}\text { Mean serum } \\
\text { albumin } \\
(G m . \%)\end{array}$ & $\begin{array}{l}(1) \\
(2)\end{array}$ & $\begin{array}{l}5.03 \\
4.28\end{array}$ & $\begin{array}{l}5.20 \\
4.94\end{array}$ & $\begin{array}{l}4.79 \\
4.29\end{array}$ & $\begin{array}{l}4.32 \\
3.99\end{array}$ \\
\hline $\begin{array}{l}\text { Mean serum } \\
\text { globulin } \\
(\mathrm{Gm} . \%)\end{array}$ & $\begin{array}{l}(1) \\
(2)\end{array}$ & $\begin{array}{l}2.94 \\
2.89\end{array}$ & $\begin{array}{l}2.73 \\
2.57\end{array}$ & $\begin{array}{l}2.50 \\
2.60\end{array}$ & $\begin{array}{l}2.90 \\
2.77\end{array}$ \\
\hline
\end{tabular}

* (1) refers to indices measured in the myxedematous state at the time of the first tracer study, (2) to measurements made at the time of the second study in the euthyroid state.

$\dagger$ These $\mathrm{NaI}^{131}$ tracers were performed in the absence of thyroid hormone or thyroid blocking agents. 


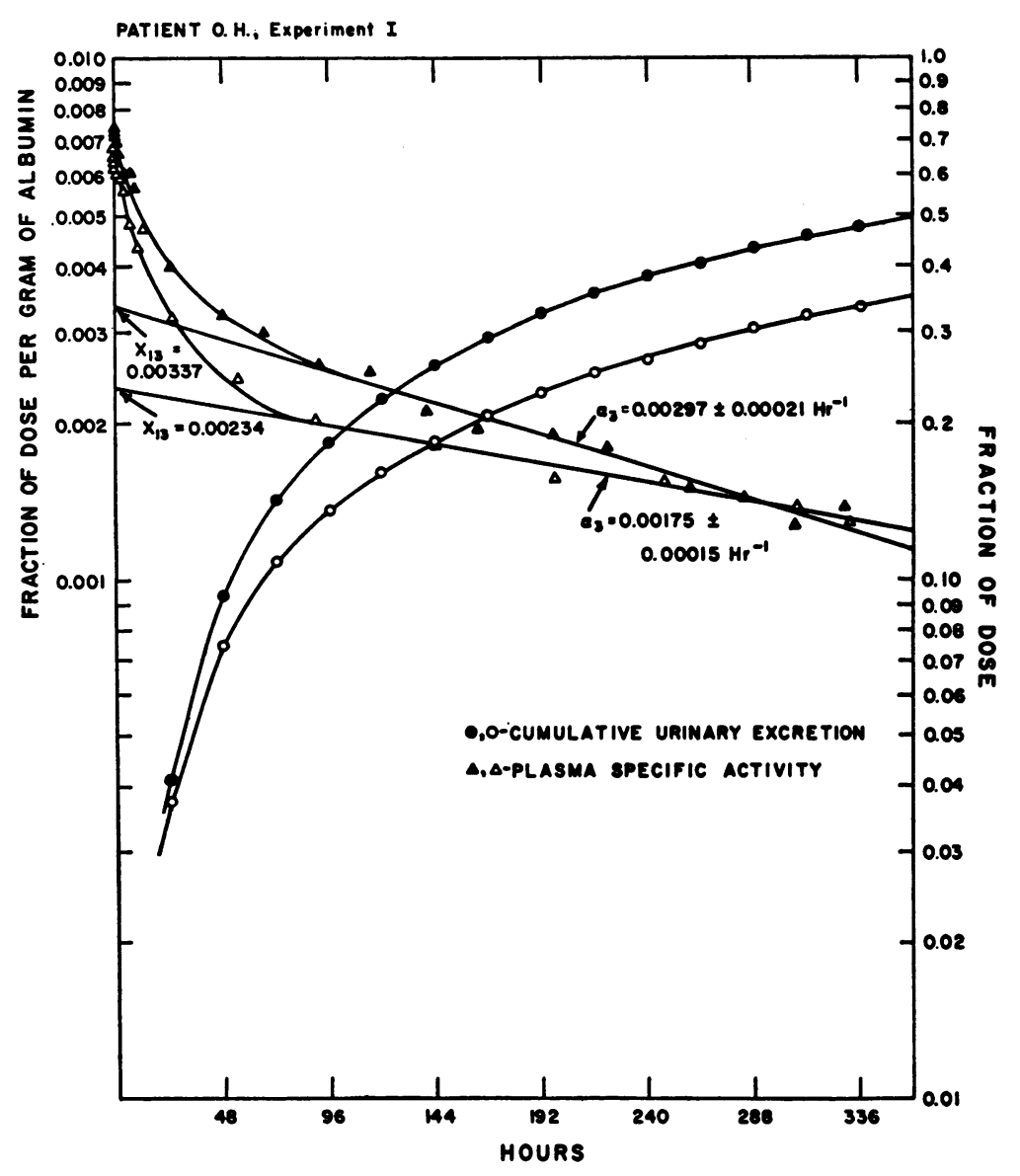

Fig. 1. I 181-IOdoalbumin Tracer StUdies

Open points indicate myxedema study; shaded points, euthyroid study.

known to have residual functioning thyroid cancer in the neck, lungs and sternum. Despite the fact that she had never received exogenous thyroid hormone, she had never developed myxedema but had shown mild hypothyroidism for the previous few years. Presumably, her tumor was producing significant but less than normal amounts of thyroid hormone. Neither antithyroid drugs nor iodide was given during the study because of the possibility of altering her metabolic status or interfering with contemplated $I^{131}$ therapy. During the study she appeared to be in a mildly hypothyroid steady state. Her weight varied from 70.4 to $71.3 \mathrm{Kg}$., her serum cholesterol from 171 to $215 \mathrm{mg}$. per cent, and her average BMR was -5 per cent. A NaI ${ }^{131}$ tracer performed shortly after completion of the iodoalbumin study showed only $\mathbf{0 . 6 0}$ urinary excretion of label in four days. Hence, little significance could be attached to her urinary excretion data from the iodoalbumin study.

In Experiment II the probable error of counting for the least active plasma and urine samples did not exceed 1.4 and 3.8 per cent, respectively.

In addition to the iodoalbumin studies, all patients were subjected to ancillary $\mathrm{NaI}^{131}$ tracer studies in either the euthyroid or myxedematous state, and the rate constant of renal iodide excretion, Kie, was computed by the approach described by Keating, Power, Berkson and Haines (5). In those instances in which Kie was determined in only one metabolic state, Kie for the other was computed from the relationship obtained from the data of Keating, Haines, Power and Williams:

$$
\frac{\text { Kie (myxedema) }}{\text { Kie (euthyroid) }} \cong 0.76 \text { (6) }
$$

\section{RESULTS AND ANALYSIS OF DATA}

The notation and terminology employed in the discussion to follow are the same as that defined elsewhere (4).

The plasma and urinary excretion data of Patient O. H., typical of the studies of Experiment I, are shown in Figure 1. It is noteworthy that in myxedema the values of $\mathrm{X}_{13}$ and $\alpha_{3}$ are considerably smaller than the respective values in the euthyroid state, and that urinary excretion 


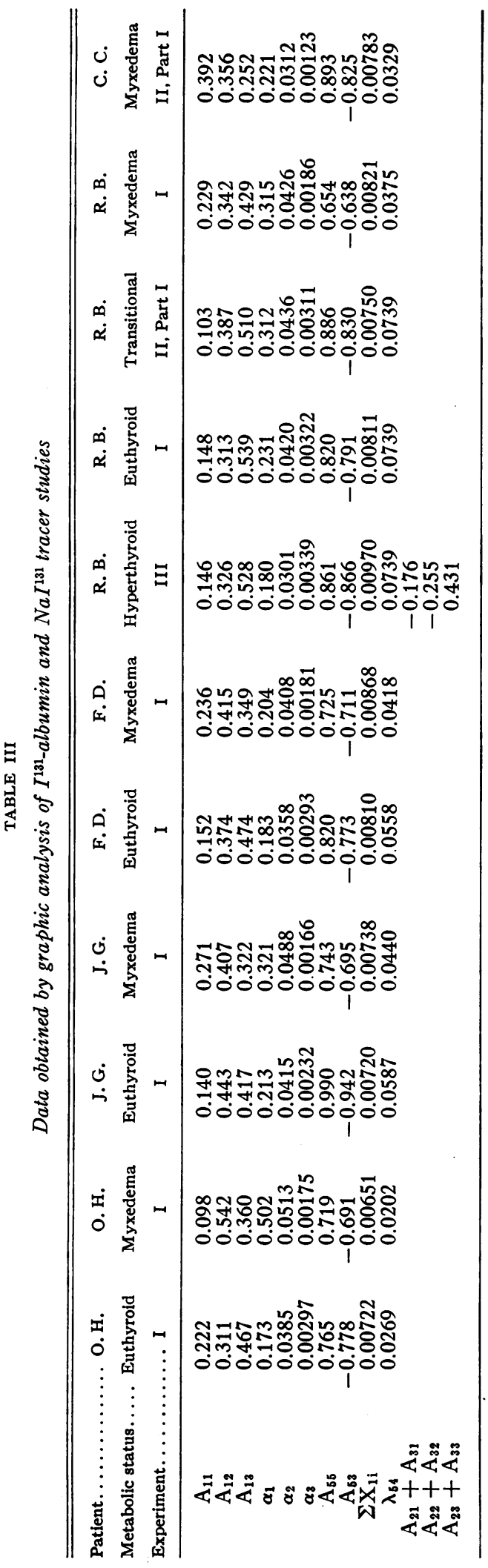

of label is appreciably faster in euthyroidism. (The first five points of the myxedema plasma curve have been shifted slightly to the left by the artist to avoid overlapping the euthyroid plasma curve.)

The plasma and urine data of Experiment I and that of Patients C. C. and R. B., Experiment II, Part 1, were subjected to graphic analysis as described elsewhere (4). The data of E. L., Experiment II, were not subjected to compartmental analysis because of the presence of unblocked, functioning metastases which presumably vitiated her excretion data. As before, the values of $\alpha_{3}$ and $\mathrm{X}_{13}$ were obtained by the method of least squares. The constants obtained from the experimental data are shown in Table III. Due to the fact that urine collections were not made more frequently than every 24 hours, graphical differentiation of the early part of the excretion curves could not be carried out and neither could the exponential components of the early portions of the excretion curves be resolved. Only the $A_{55}$ and $A_{53}$ components from the terminal portions of the curves could be reliably determined from the data.

The formulation of an open system of three exchanging compartments and three nonexchanging compartments and its mathematical solution have been described previously. When the most reliable and complete set of iodoalbumin tracer data at our disposal (R. B., Experiment III) were subjected to this analysis, the best obtainable fit of the data occurred with $\lambda_{01}=0$. The data of R. B., Experiment III, were shown to contain seven of the nine experimentally measured constants required for a complete solution of the general system of three exchanging compartments. The solution was therefore not unique. Four "simplest" models were shown to exist that are compatible with the data, physically realizable, and equally probable to be the "right model" on the basis of the tracer data only (4). One of these, the parallel model, was considered most likely on the basis of physiological considerations and is the model arbitrarily chosen for this presentation.

It should be noted that the data shown in Table III (excepting R. B., Experiment III) contain as such only five of the nine independent constants of a general system of three exchanging 
compartments: three $\alpha$ 's and two A's from $\mathrm{q}_{1}(\mathrm{t})$. The additional measured values of $A_{55}, A_{53}$ and $\lambda_{54}$ permit evaluation of a sixth independent constant $\left(A_{23}+A_{33}\right)$ from the relation

$$
\left(A_{23}+A_{33}\right)=-A_{13}+\frac{A_{53} \alpha_{3}}{A_{55} \lambda_{54}}-\frac{A_{53}}{A_{55}} .
$$

This equation follows from the general relation, $\sum_{j} A_{j i}=0$, for the multicompartment system previously described and is independent of the configuration of the three exchanging compartments. The solutions for the tracer studies reported here follow the same procedures as outlined in our previous paper (4) with the three constraints that $\lambda_{23}=\lambda_{32}=\lambda_{01}=0$. Newly synthesized carrier is assumed to enter Compartment 1 . The assumptions regarding Compartment 6 are the same as those previously given. The model is shown in Figure 2.

The results of the solution are given in Table IV. In the extreme right column is given, for several of the solution parameters, the mean ratio of their value in myxedema to their value in the euthyroid state. Patient C. C. was not studied in a euthyroid steady state. The results

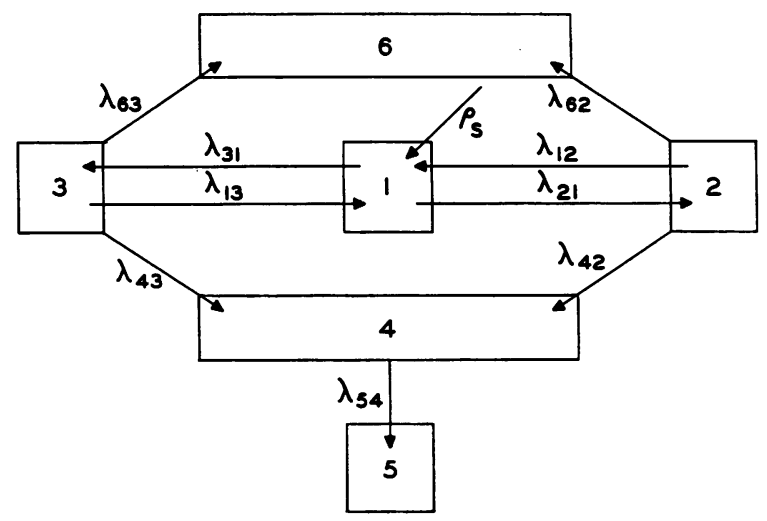

Fig. 2. Diagrammatic Representation of Model Used FOR ANALYSIS OF DATA OF EXPERIMENTS I AND II

The model consists of three exchanging compartments (1, 2 and 3$)$ and three nonexchanging compartments $(4,5$ and 6). Compartment 1 is plasma, the sampled compartment. Compartments 2 and 3 are, respectively, rapidly and slowly exchanging extravascular compartments. Compartment 4 represents nonexcreted degradation products. Compartment 5 is collected urine. Compartment 6 is a body compartment treated analytically as a nonexchanging compartment. Newly synthesized carrier is assumed to enter Compartment 1 at the rate $\rho_{\mathrm{s}}$. The model shown assumes $\left(\lambda_{61}+\lambda_{41}\right) \equiv \lambda_{01}=\lambda_{32}=\lambda_{23}=0$. of the myxedema study (Experiment II, Part 1) are included because this patient showed the highest value of $S_{T}$ and the lowest value of $\lambda_{4 T}$ encountered in the studies. The results of the study on R. B., Experiment III, published elsewhere (4), are included here to show the stepwise change seen in the solution parameters under the conditions of varied metabolic status.

It should be noted that in all the studies listed, except that of R. B., Experiment III, the values of $\lambda_{43}$ and $\lambda_{63}$ and the corresponding $\rho$ 's are of negative sign. This represents a systematic inconsistency between the data and the model used for the analysis. Further study of the inconsistency by the mapping procedure described previously (4) indicated that the inconsistency does not result from choice of the parallel model since a mapping of the data did not show a region of physical realizability. An average increase in the value of $\left(\mathrm{A}_{23}+\mathrm{A}_{33}\right)$ of 7 per cent resulted in a physically realizable solution for all the tracer studies, and one way by which a realizable fit to the parallel model could be obtained was to increase the value of $\left(\mathrm{A}_{23}+\mathrm{A}_{33}\right)$ by at most 25 per cent. This systematic inconsistency could also result from a systematic error in evaluating $\lambda_{54}$, nonvalidity of the assumption that $\mathrm{q}_{6}(\mathrm{t})$ is proportional to $\mathrm{q}_{4}(\mathrm{t})+\mathrm{q}_{5}(\mathrm{t})$, or from the presence in the labeled material of components degraded at different rates (7). In view of the relatively small magnitude of the inconsistency it was considered preferable to present the solution in its inconsistent form rather than to introduce additional assumptions.

When constraints are introduced and inconsistencies are encountered (as here) it is advisable to consider which solution parameters are independent of the constraints. In our previous paper (4) it was pointed out that $S_{1}, \lambda_{11}$ and $\lambda_{22}+\lambda_{33}$ are dependent only on time measurements of Compartment 1 and are thereby independent of the choice of model. Granted $\lambda_{01}=0$ (evidence restricted to data of Experiment III), $\lambda_{21}+\lambda_{31}$ is constant for all models. Granted, in addition, entry of new carrier into Compartment $1, S_{2}+S_{3}$ and $S_{1}+S_{2}+S_{3}$ are constant for all models.

Table IV shows an average increase of $S_{T}$ in myxedema of 31 per cent. All of this increase can be accounted for by the 70 per cent increase 
CHARLES G. LEWALlen, JOSEPH E. RALL, AND MONES BERMAN

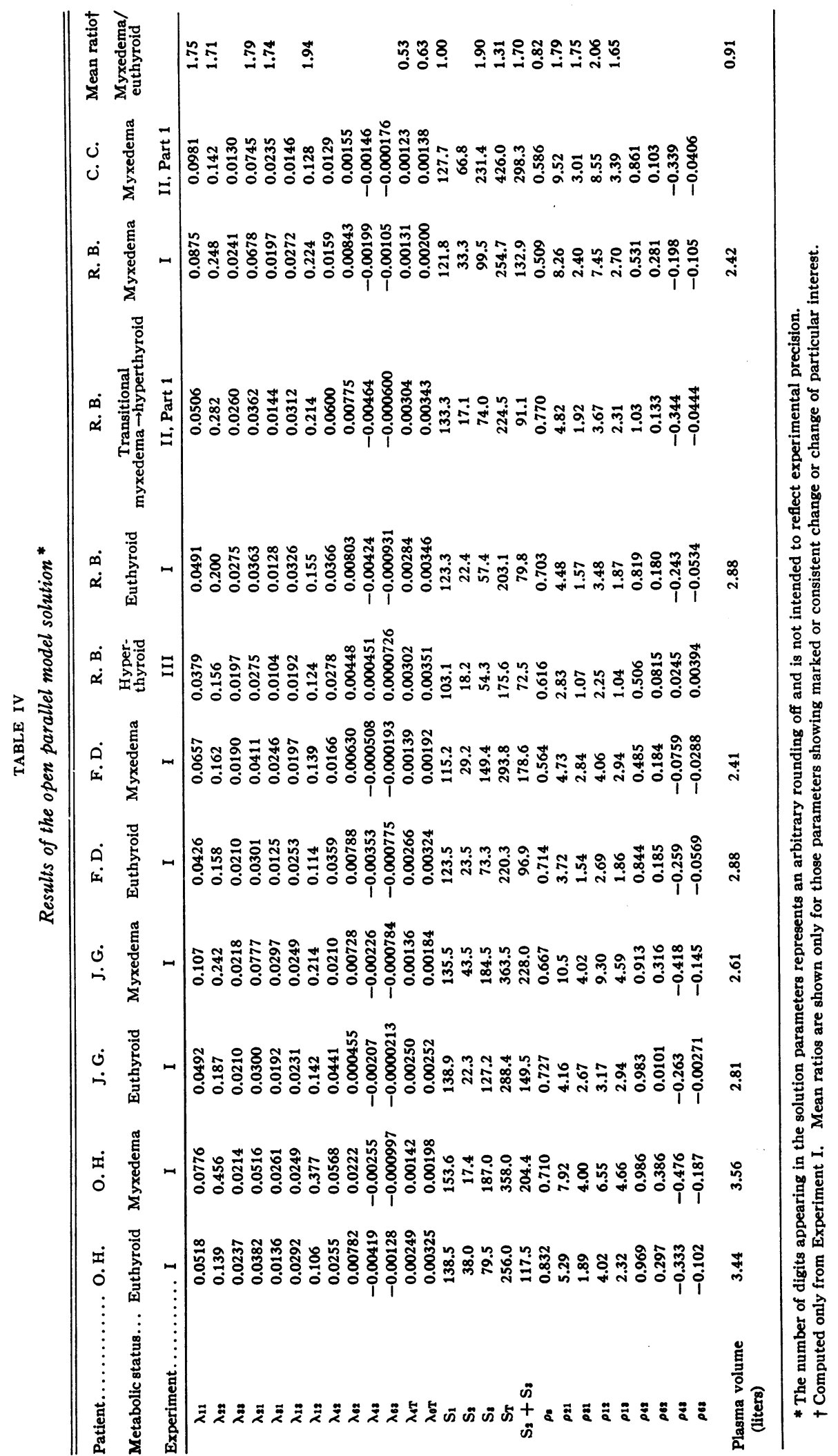




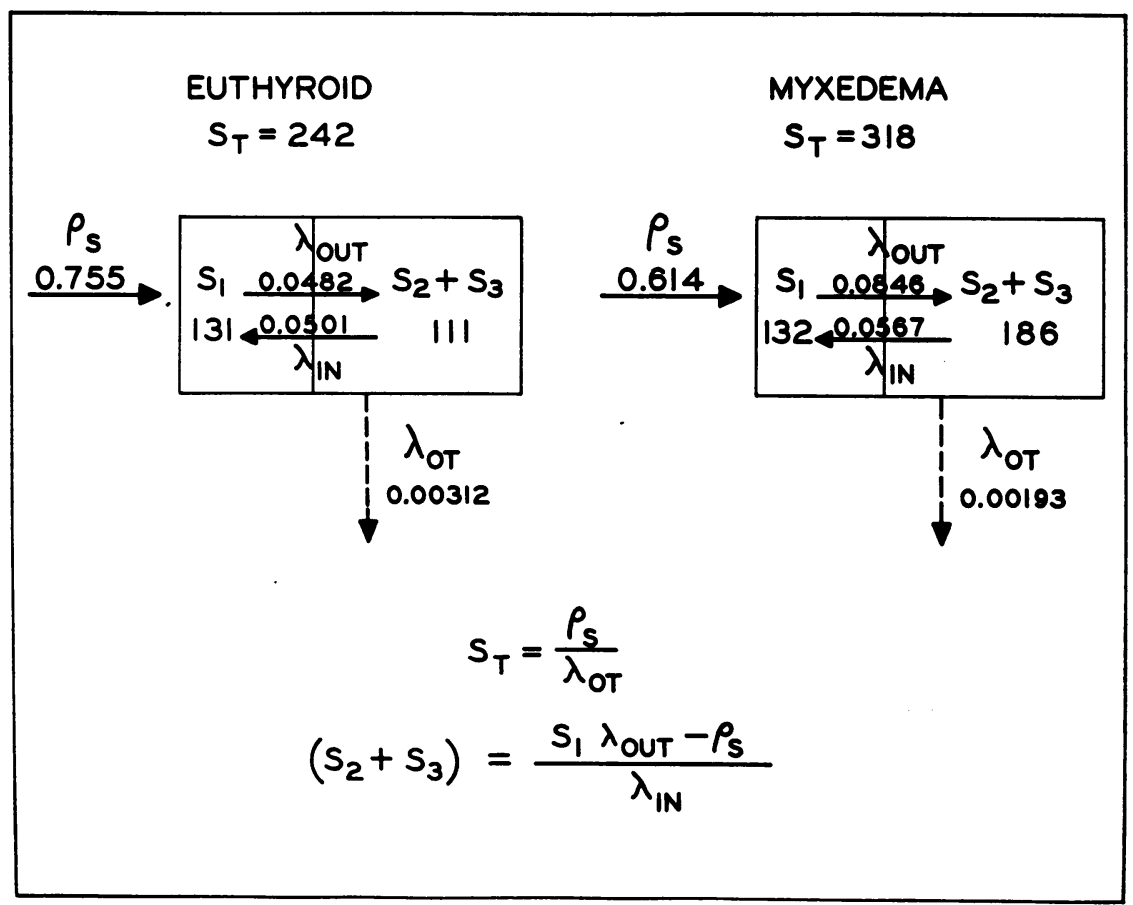

Fig. 3. Simplified Diagrammatic Representation of Albumin Metabolism KinETICS IN EUTHYROIDISM AND MYXEDEMA

in extravascular carrier, $S_{2}+S_{3}$, since there is no appreciable change in plasma albumin, $S_{1}$. Furthermore, the increase in $\mathrm{S}_{2}+\mathrm{S}_{3}$ is almost entirely accounted for by the 90 per cent increase in $S_{3}$, the carrier of the slowly exchanging extravascular compartment.

Some insight into the development of this situation may be gained from the following considerations. In Figure 3, for purposes of clarity, the model has been simplified by combining Compartments 2 and 3 into a single extravascular compartment. In the figure

$$
\begin{aligned}
\lambda_{\text {out }} & \equiv \lambda_{21}+\lambda_{31}, \\
\lambda_{\text {in }} & \equiv \frac{\rho_{12}+\rho_{13}}{S_{2}+S_{3}},
\end{aligned}
$$

the latter to give an average value for the fractional rate of transport of albumin from the extravascular compartments to plasma. The average state of affairs in euthyroidism and myxedema is depicted. The solution values shown are the mean values of the parameters in the two metabolic states taken from Table IV with the exception of $\lambda_{i n}$ and $\rho_{s}$ which were altered slightly (less than 4 per cent) to "balance" the models shown.
In any given steady state where the rate of carrier synthesis is equal to the rate of carrier loss, the following relationship must hold:

$$
\rho_{\mathrm{s}}=\mathrm{S}_{\mathrm{T}} \lambda_{0 \mathrm{~T}}, \quad \mathrm{~S}_{\mathrm{T}}=\frac{\rho_{\mathrm{s}}}{\lambda_{0 \mathrm{~T}}} .
$$

Consideration of this relationship and Figure 3 shows that, from a descriptive standpoint at least, the increase in $S_{T}$ in myxedema is associated with a marked reduction in $\lambda_{0 \mathrm{~T}}$ and cannot be attributed to a change in the rate of synthesis, since a considerable increase in the carrier of the system occurs despite a reduction in the rate of synthesis. It is of considerable interest that the increase in total carrier, explainable in terms of a reduction in the fractional rate of loss of carrier from the system as a whole, is confined to the extravascular compartments. From Figure 3 it is apparent:

$$
\begin{gathered}
\left(\mathrm{S}_{2}+\mathrm{S}_{3}\right) \lambda_{\text {in }}+\rho_{\mathrm{s}}=\mathrm{S}_{1} \lambda_{\text {out }} \\
\mathrm{S}_{2}+\mathrm{S}_{3}=\frac{\mathrm{S}_{1} \lambda_{\text {out }}-\rho_{\mathrm{s}}}{\lambda_{\text {in }}} .
\end{gathered}
$$

Consideration of this relationship and Figure 3 reveals that the confinement of the increase in carrier in myxedema to extravascular sites is 


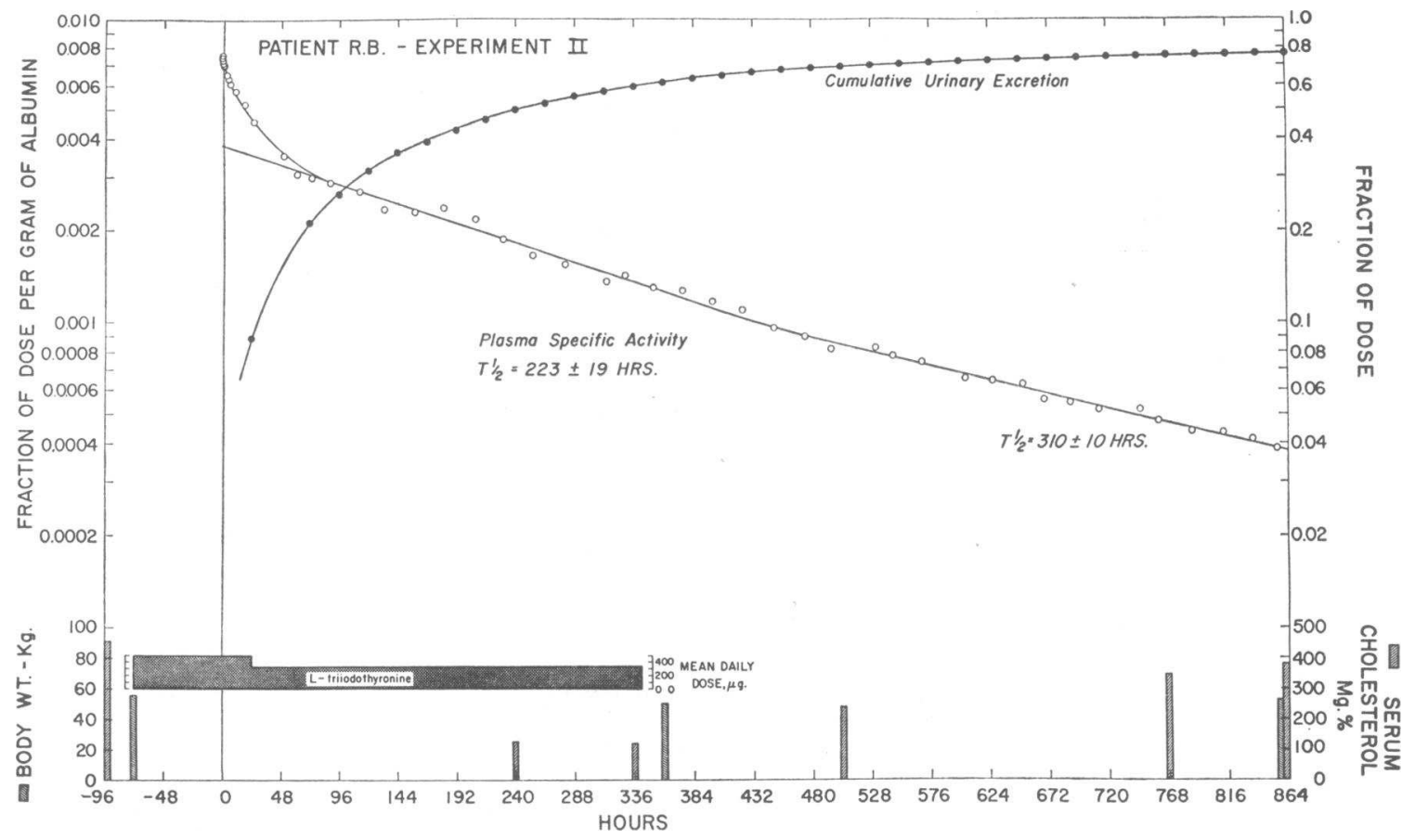

Fig. 4. The Effects of the Withdrawal of Thyroid Hormone on Plasma Specific Activity and URINARY EXCRETION OF LABEL

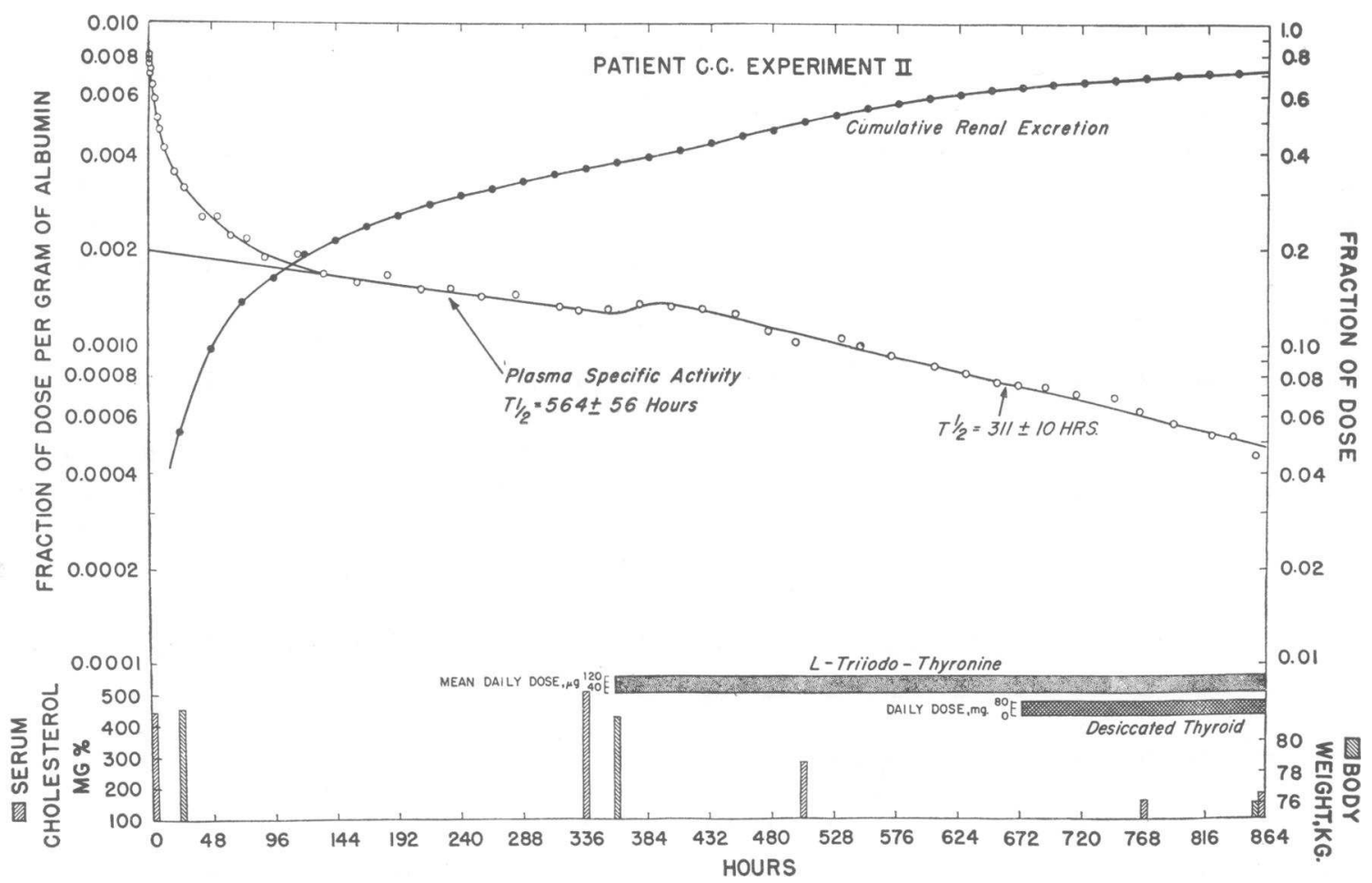

Fig. 5. The Effects of Administration of Thyroid Hormone to a Myxedematous Subject on Plasma Specific Activity and Urinary Excretion of Label 
primarily a reflection of the marked increase in $\lambda_{\text {out }}$, since the change in $S_{1}$ is insignificant. The change in $\rho_{s}$ contributes little to the right side of the equation, and the change in $\lambda_{\text {in }}$ is in the wrong direction to effect an increase in $S_{2}+S_{3}$. Table IV shows that a marked increase in the outward transcapillary transport rate of albumin was a consistent finding in these studies.

Altogether, Patient R. B. was studied in four metabolic states. The results of all four studies show a gradation of change in the solution parameters. The solution described above is applicable only to the steady state $\left(\rho_{\mathrm{s}}=\mathrm{S}_{\mathrm{T}} \lambda_{0 \mathrm{~T}}\right)$. The study designated "transitional" thyroid status was performed in a presumably unsteady state at a time when the patient was being rapidly converted from a myxedematous to a hyperthyroid status with triiodothyronine. Strictly speaking, this study is not amenable to the analysis outlined. However, it was considered likely that the hormone was exerting its effects primarily on the rates in the system and that changes in compartment sizes during the time of the study would probably be of insufficient magnitude to alter seriously the validity of the analysis. Attention is called to the orderly change in many of the solution parameters proceeding in sequence through the metabolic states designated as hyperthyroid, euthyroid, transitional and myxedematous.

In the studies of Experiment I, each patient served as his own control as far as metabolic status is concerned. However, in any one patient the euthyroid and myxedema studies were carried out with different batches of iodoalbumin, so that conceivably the results shown in the table might be explainable, at least in part, by differences in the tracer material used in the myxedema and euthyroid studies. In part, Experiment II was performed to study this possibility. The plasma specific activity and urinary excretion curves for the three patients are shown in Figures 4, 5 and 6. The patient, E. L., whose metabolic status was unchanged, shows a single final component of plasma specific activity after the "mixing" phase. The decrease in slope of the plasma curve produced by withdrawal of thyroid hormone in R. B. and the increase in slope produced by administration of hormone in C. C. are statistically significant. Compartment analysis of Part 2 of these experiments (after withdrawal and addition of hormone, respectively) is of course not possible, and, as previously shown (4), the final plasma slopes cannot be regarded as more than an approximation to $\lambda_{0 \mathrm{~T}}$. It is evident, however, that the changes in slope observed are similar in direction and magnitude to the changes in $\lambda_{0 \mathrm{~T}}$ noted in the "before and after" type of studies in Experiment I. This would appear to eliminate the possibility that the changes in $\lambda_{0 \mathrm{~T}}$ noted in Experiment $\mathrm{I}$ are a result of some factor other than hormone action. All three patients in this experiment were given

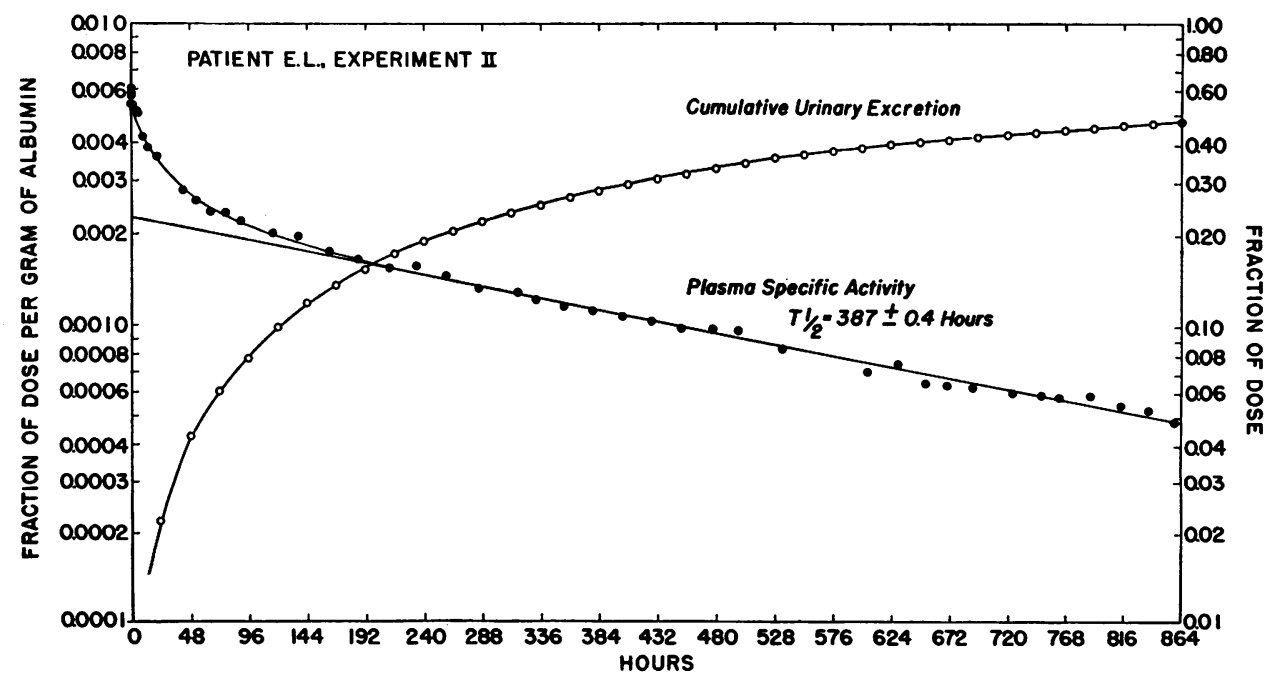

Fig. 6. 36 Day Tracer Study in a Mildly Hypothyroid Patient

The metabolic status underwent no apparent change during the study. 
identical aliquots of the same batch of iodoalbumin on the same day.

\section{DISCUSSION}

As noted above, the overall increase in carrier albumin in myxedema is associated, at least descriptively, with a reduction in the overall fractional rate of loss of carrier, $\lambda_{0 \mathrm{~T}}$, from the system. The analysis indicates that thyroid hormone effects an increase in the absolute rates of synthesis, $\rho_{\mathrm{s}}$, and of loss, $\rho_{\mathrm{L}}$. Furthermore, confinement of the increase in carrier albumin in myxedema to extravascular sites would appear to be a result of the increase in outward transcapillary transport rate of albumin, rather than of some factor slowing the return of albumin from extravascular sites to plasma.

It is of some interest to speculate whether the primary effect of the hormone is on the fractional rate of loss of carrier, $\lambda_{0 \mathrm{~T}}$, or on the absolute rate of loss, $\rho_{\mathrm{L}}$. We favor the former rather than the latter possibility. If the former were correct, one would expect hormone administration to produce an increased rate of synthesis, $\rho_{\mathbf{s}}{ }^{\prime}$, and an increased fractional rate of loss $\lambda_{0 \mathrm{~T}^{\prime}}$, and that this would produce a progressive reduction in $S_{T}$ and automatically reach a new steady state where $\rho_{\mathrm{s}}{ }^{\prime}=\mathrm{S}_{\mathrm{T}}{ }^{\prime} \lambda_{0 \mathrm{~T}}{ }^{\prime}=\rho_{\mathrm{L}}{ }^{\prime}$. This point of view requires no direct coupling of the rates of synthesis and degradation which are, however, equal in any given steady state.

With the latter possibility one would have to postulate from hormone administration an increased rate of synthesis, $\rho_{\mathrm{s}}{ }^{\prime}$, and of loss, $\rho_{\mathrm{L}}{ }^{\prime}$, where $\rho_{\mathrm{L}}{ }^{\prime}>\rho_{\mathrm{s}}{ }^{\prime}$. This would result in a progressive reduction in $S_{T}$ but one is then left with the problem of some compensatory mechanism whereby, as the new steady state is approached, either $\rho_{\mathrm{L}}{ }^{\prime}$ or $\rho_{\mathrm{s}}{ }^{\prime}$ is again changed such that $\rho_{\mathrm{L}}{ }^{\prime}=\rho_{\mathrm{s}}{ }^{\prime}$. Furthermore, with the latter possibility the change in $\lambda_{0 \mathrm{~T}}$ is a secondary one, and since $\lambda_{0 \mathrm{~T}^{\prime}}{ }^{\prime}=\frac{\rho_{\mathrm{L}}{ }^{\prime}}{\mathrm{S}_{\mathrm{T}^{\prime}}}$, it is clear that during the transition phase after administration of hormone, one would not expect to see the full change in $\lambda_{0 T}$ until $S_{T}$ had reached its final, minimal value. In this connection it is of interest that the "transitional" study on R. B. shows a euthyroid value for $\lambda_{0 \mathrm{~T}}$ despite the fact that an elevation of $S_{T}$ still persists. The nonvalidity of the applica- tion of the kinetic analysis to this particular study, however, allows little weight to be placed on this evidence. Additional evidence on this point is available from the studies of Gitlin, Janeway and Farr (8) who showed that plasmaphoresis in dogs and chronic bleeding in mice did not increase the fractional rate of catabolism of homologous albumin.

The questionable validity of iodoalbumin as a tracer for native albumin catabolism has been discussed elsewhere (4). In addition, the studies of Steinfeld and co-workers (9) show a more rapid degradation-excretion of the particular type of iodoalbumin employed by us than that from several other preparations tested. In view of this, the absolute values of $\rho_{\mathrm{s}}$ and $\lambda_{0 \mathrm{~T}}$ shown in Table IV should be regarded as only approximations, probably in error by overestimation. [The validity of the tracer material used in the study of R. B., Experiment III, is less subject to question (4).]

Despite these objections, the controlled manner in which Experiment I was carried out and the results of Experiment II would appear to leave little doubt as to the effect of both desiccated thyroid and L-triiodothyronine on the distribution kinetics and degradation of the iodoalbumin preparation used.

The results of these kinetic studies of serum albumin behavior are more meaningful when considered in conjunction with certain aspects of its metabolism revealed by other approaches. There is excellent experimental evidence that the liver (at least in the rat) is the dominant, if not the sole, site of albumin synthesis $(10,11)$. In the isolated perfused rat liver albumin labeled in the liver is capable of entering the perfusion system via the hepatic veins (10). Once in the circulating blood, albumin is transported across the capillary wall to the interstitial fluid and body cavity fluids. It is probable that the transport of albumin from the interstitial fluid to plasma is almost exclusively via lymphatics rather than by re-entry of blood capillaries (12). Under normal conditions tracer studies reveal a roughly equal partition of total exchangeable albumin between intravascular and extravascular sites $(13,7)$. On the basis of biopsy and autopsy studies of patients given I'131-albumin Rothschild, Bauman, Yalow and Berson computed that 
plasma, interstitial fluid of skin and interstitial fluid of muscle accounted for 40,18 and 15 per cent, respectively, of total exchangeable albumin (14). Utilizing the fluorescent antibody technique, Gitlin, Landing and Whipple (15) have demonstrated homologous serum albumin intracellularly in a variety of human tissues. In addition, it seems clear that circulating albumin may serve as a general body nitrogen source (16).

Studies similar to those of Experiment I of this paper were carried out by Schwartz on two patients with myxedema and analyzed by slope, intercept and dilution methods (17). Although the data in one patient did not permit satisfactory comparison of plasma slopes before and after treatment, the findings relative to the changes in total exchangeable albumin, extravascular albumin, total turnover rate and rate of synthesis produced by thyroid hormone in myxedema are in substantial agreement with the results reported here.

In experiments conducted by Dixon, Talmage, Maurer and Deichmiller (18) employing $\mathrm{I}^{131}$ gamma globulin, thyroxine administered to rabbits in a dosage sufficient to double their oxygen consumption resulted in a 30 per cent increase in the final plasma slope. Similarly, Rothschild, Bauman, Yalow and Berson (19) administered $\mathrm{I}^{131}$-albumin to previously euthyroid patients receiving large doses of desiccated thyroid. Increases in the fractional rate of degradation, the absolute rate of degradation and the synthetic rate of serum albumin were observed along with a reduction in total exchangeable albumin.

The results of the present study and those of other investigators cited above $(17,19)$ are in substantial agreement regarding the increase in rate of synthesis, increase in fractional rate of catabolism and reduction of total exchangeable albumin produced by thyroid hormone. These studies, however, shed no light on the mechanism whereby these changes are effected. Steinbock and Tarver have shown that the turnover rate of plasma protein is directly related to the protein content of the diet (20). This aspect of the problem was not controlled in our experiments. It would appear unlikely, however, that the changes observed here were produced by a change in protein intake. In the study of C. C., Experiment II (see Figure 5), an increase in the rate of renal excretion of label was evident as early as $\mathbf{4 8}$ hours after administration of triiodothyronine. At this time the patient was experiencing the anorexia, malaise and headache commonly seen in myxedematous patients in the first few days after the start of thyroid hormone.

Whether the observed results are a direct or indirect effect of thyroid hormone is not clear. Although the effects of thyroid hormone on overall nitrogen metabolism are not necessarily relevant to its effect on the metabolism of a single plasma protein, the overall catabolic effect of thyroid hormone in both euthyroid and myxedematous subjects has been well documented (21-23). Studies in rats with $\mathrm{N}^{15}$-glycine by Hoberman and Graff (24) suggest that thyroxine decreases amino acid catabolism and increases the breakdown of body protein to amino acids. The marked increase in transcapillary transport of albumin in the present studies was a somewhat unexpected but consistent finding. The data of Lange are of interest in this connection (25). This investigator injected fluorescein intravenously and showed that the dye appeared in the skin of myxedematous subjects much more rapidly than in normal controls. He concluded that there is an increase in capillary permeability in myxedema.

On the other hand, White and Jones (26), using the pressure plethysmograph, observed in myxedema a reduction in the rate of filtration of fluid across the capillary bed of the arm in response to venous congestion. However, it has been demonstrated by Pappenheimer and SotoRivera (27) that in the mammalian circulatory system the permeability of the capillary walls to protein need not necessarily be related to its permeability to fluid.

The anatomical changes in the capillaries of the human ungual fold in myxedema have been studied in the living state by Zondek, Michael and Kaatz (28). The principal changes observed consisted of reduction in the number of visible capillaries, an increase in the intercapillary spaces, a reduction in caliber, a reduction in tortuosity and a loss of the normal discrepancy between the widths of the arterial and venous limbs.

We have no satisfactory explanation for the observed increase in the rate of transcapillary passage of albumin in myxedema. An increase 
in capillary pressure and severe anoxia have been shown to produce an increase in the rate of passage of protein across the capillary wall. In studies by Landis, Jonas, Angevine and Erb, a venous congestion pressure above $60 \mathrm{~mm}$. of mercury was required to demonstrate the effect (29). In edema fluid produced by prolonged venous congestion Stead and Warren demonstrated an increase in protein concentration by a congestion pressure of $30 \mathrm{~mm}$. $\mathrm{Hg}$ (30). In these instances, the resulting capillary pressure is probably approximately 8 to $14 \mathrm{~mm}$. Hg greater than the congestion pressure (31), such that the increase in capillary pressure above normal is at least 50 per cent. We are not aware of any direct determinations of capillary pressure in myxedema. The mean increase in plasma colloid osmotic pressure in myxedema in the patients of Experiment I computed from their plasma protein concentrations was only 15 per cent (32). Although the mean capillary pressure cannot be computed from the plasma colloid osmotic pressure without assumptions regarding interstitial fluid colloid osmotic pressure and tissue pressure (27), these considerations suggest that the changes in capillary pressure in myxedema, if any, are small, and are probably not the explanation for the marked increase in transcapillary passage of albumin. Although severe anoxia will produce an increase in capillary permeability to both water and plasma protein (33), Stead and Warren (30) found low protein concentrations in the edema fluid from patients with severe reduction in arterial oxygen saturation, from which they concluded that anoxia of a degree sufficient to produce an increased capillary permeability to protein was incompatible with life.

The mean change in plasma volume observed after administration of thyroid hormone (an increase of 10 per cent) is less than the 23 per cent increase reported by Thompson (34).

\section{SUMMARY AND CONCLUSIONS}

Four patients with myxedema were subjected to tracer studies with $I^{181}$-iodoalbumin before and after treatment with thyroid hormone. Two patients were studied by altering their metabolic status during a tracer study. One patient was given tracer studies in four metabolic states.
The data were analyzed with reference to an open, multicompartment parallel model.

The analysis indicated that there is in myxedema an increase in total exchangeable albumin which is confined to the extravascular compartments, a reduction in the rate of albumin synthesis and catabolism, a reduction in the fractional rate of albumin catabolism, an increase in the transcapillary transport rate of albumin and a reduction in plasma volume. In patients in whom the metabolic status was altered during tracer experiments the changes in the urinary excretion and plasma curves were consistent with the results of steady state tracer experiments in the euthyroid and myxedematous states.

\section{REFERENCES}

1. Lewallen, C. G., Rall, J. E., Berman, M., and Hamel, H. The effects of thyroid hormone on the distribution kinetics and degradation of iodoalbumin (abstract). J. clin. Invest. 1955, 34, 949.

2. Kingsley, G. R. A rapid method for the separation of serum albumin and globulin. J. biol. Chem. 1940, 133, 731.

3. Hiller, A., Plazin, J., and Van Slyke, D. D. A study of conditions for Kjeldahl determination of nitrogen in proteins. Description of methods with mercury as catalyst, and titrimetric and gasometric measurements of the ammonia formed. J. biol. Chem. 1948, 176, 1401.

4. Lewallen, C. G., Berman, M., and Rall, J. E. Studies of iodoalbumin metabolism. I. A mathematical approach to the kinetics. J. clin. Invest. 1959, 38, 66.

5. Keating, F. R., Jr., Power, M. H., Berkson, J., and Haines, S. F. The urinary excretion of radioiodine in various thyroid states. J. clin. Invest. 1947, 26, 1138.

6. Keating, F. R., Jr., Haines, S. F., Power, M. H., and Williams, M. D. The radioiodine-accumulating function of the human thyroid gland as a diagnostic test in clinical medicine. J. clin. Endocr. 1950, 10, 1425.

7. Berson, S. A., Yalow, R. S., Schreiber, S. S., and Post, J. Tracer experiments with $I^{131}$ labeled human serum albumin: Distribution and degradation studies. J. clin. Invest. 1953, 32, 746.

8. Gitlin, D., Janeway, C. A., and Farr, L. E. Studies on the metabolism of plasma proteins in the nephrotic syndrome. I. Albumin, $\gamma$-globulin and iron-binding globulin. J. clin. Invest. 1956, 35, 44.

9. Steinfeld, J. L., Paton, R. R., Flick, A. L., Milch, R. A., Beach, F. E., and Tabern, D. L. Distribution and degradation of human serum albumin labeled with $\mathrm{I}^{131}$ by different techniques. Ann. N. Y. Acad. Sci. 1957, 70, 109. 
10. Miller, L. L., Bly, C. G., Watson, M. L., and Bale, W. F. The dominant role of the liver in plasma protein synthesis. A direct study of the isolated perfused rat liver with the aid of lysine- $\epsilon-C^{14}$. J. exp. Med. 1951, 94, 431.

11. Miller, L. L., Bly, C. G., and Bale, W. F. Plasma and tissue proteins produced by non-hepatic rat organs as studied with lysine- $\epsilon-C^{14}$. Gamma globulins the chief plasma protein fraction produced by non-hepatic tissues. J. exp. Med. 1954, 99, 133.

12. Yoffey, J. M., and Courtice, F. C. Lymphatics, Lymph, and Lymphoid Tissue. Cambridge, Mass., Harvard University Press, 1956, ch. 2.

13. Sterling, $K$. The turnover rate of serum albumin in man as measured by $\mathrm{I}^{131}$-tagged albumin. J. clin. Invest. 1951, 30, 1228.

14. Rothschild, M. A., Bauman, A., Yalow, R. S., and Berson, S. A. Tissue distribution of $I^{131}$ labeled human serum albumin following intravenous administration. J. clin. Invest. 1955, 34, 1354.

15. Gitlin, D., Landing, B. H., and Whipple, A. The localization of homologous plasma proteins in the tissues of young human beings as demonstrated with fluorescent anti-bodies. J. exp. Med. 1953, 97, 163.

16. Eckhardt, R. D., Lewis, J. H., Murphy, T. L., Batchelor, W. H., and Davidson, C. S. Chemical, clinical and immunologic studies on the products of human plasma fractionation. XXXIV. Comparative studies of the nutritive value of orally and intravenously administered human serum albumin in man. J. clin. Invest. 1948, 27, 119.

17. Schwartz, E. The effect of thyroid hormone upon the degradation rate and miscible pool of radioiodinated human serum albumin in myxedema. J. Lab. clin. Med. 1955, 45, 340.

18. Dixon, F. J., Talmage, D. W., Maurer, P. H., and Deichmiller, M. The half-life of homologous gamma globulin (antibody) in several species. J. exp. Med. 1952, 96, 313.

19. Rothschild, M. A., Bauman, A., Yalow, R. S., and Berson, S. A. The effect of large doses of desiccated thyroid on the distribution and metabolism of albumin-I'181 in euthyroid subjects. J. clin. Invest. 1957, 36, 422.

20. Steinbock, H. L., and Tarver, H. Plasma protein. V. The effect of the protein content of the diet on turnover. J. biol. Chem. 1954, 209, 127.

21. Ord, W. M., and White, E. Clinical remarks on certain changes observed in the urine in myxedema after the administration of glycerine extract of thyroid gland. Brit. med. J. 1893, 2, 217.
22. Boothby, W. M., Sandiford, I., Sandiford, K., and Slosse, J. The effect of thyroxin on the respiratory and nitrogenous metabolism of normal and myxedematous subjects. I. A method of studying the reserve or deposit protein with a preliminary report on the results obtained. Ergebn. Physiol. 1925, 24, 728.

23. Byrom, F. B. The nature of myxoedema. Clin. Sci. 1934, 1, 273.

24. Hoberman, H. D., and Graff, J. Influence of thyroxine on the metabolism of amino acids and proteins during fasting. Yale J. Biol. Med. 1950, 23, 195.

25. Lange, K. Capillary permeability in myxedema. Amer. J. med. Sci. 1944, 208, 5.

26. White, B. V., and Jones, C. M. The rate of filtration through the capillary walls as measured by the pressure plethysmograph. Observations on control subjects and on patients with intrahepatic disease, thyrotoxicosis, and myxedema. J. clin. Invest. 1939, 18, 73.

27. Pappenheimer, J. R., and Soto-Rivera, A. Effective osmotic pressure of the plasma proteins and other quantities associated with the capillary circulation in the hind limbs of cats and dogs. Amer. J. Physiol. 1948, 152, 471.

28. Zondek, H., Michael, M., and Kaatz, A. The capillaries in myxedema. Amer. J. med. Sci. 1941, 202, 435.

29. Landis, E. M., Jonas, L., Angevine, M., and Erb, W. The passage of fluid and protein through the human capillary wall during venous congestion. $\mathrm{J}$. clin. Invest. 1932, 11, 717.

30. Stead, E. A., Jr., and Warren, J. V. The protein content of the extracellular fluid in normal subjects after venous congestion and in patients with cardiac failure, anoxemia, and fever. J. clin. Invest. 1944, 23, 283.

31. Landis, E. M. Micro-injection studies of capillary blood pressure in human skin. Heart 1930, 15, 209.

32. Wells, H. S., Youmans, J. B., and Miller, D. G., Jr. A formula and nomogram for the estimation of the osmotic pressure of colloids from the albumin and total protein concentrations of human blood sera. J. clin. Invest. 1933, 12, 1103.

33. Landis, E. M. Micro-injection studies of capillary permeability. III. The effect of lack of oxygen on the permeability of the capillary wall to fluid and to the plasma proteins. Amer. J. Physiol. 1928, 83, 528.

34. Thompson, W. O. Studies in blood volume. I. The blood volume in myxedema, with a comparison of plasma volume changes in myxedema and cardiac edema. J. clin. Invest., 1926, 2, 477. 